\title{
Degradation and intrahepatic compatibility of albumin-heparin conjugate microspheres
}

\author{
H.F.M. Cremers* ${ }^{*}$ R.F.E. Wolf ${ }^{\dagger}$, E.H. Blaauw ${ }^{\dagger}$, J.M. Schakenraad ${ }^{\ddagger}$, \\ K.H. Lam ${ }^{\dagger}$, P. Nieuwenhuis ${ }^{\dagger}$, R. Verrijk ${ }^{\S}$, G. Kwon", Y.H. Bae ${ }^{\|}$, \\ S.W. Kim" ${ }^{\|}$and J. Feijen* \\ "Department of Chemical Technology, University of Twente, PO Box 217, 7500 AE Enschede, The Netherlands; \\ ${ }^{\dagger}$ Department of Histology and Cell Biology, University of Groningen, Oostersingel 69IIII, 9713 EZ Groningen, The \\ Netherlands; ${ }^{\ddagger}$ Center for Biomedical Technology, University of Groningen, Oostersingel 59, Building 25, $9713 E Z$ \\ Groningen, The Netherlands; "Division of Experimental Therapy, The Netherlands Cancer Institute, Plesmanlaan \\ 121, $1066 \mathrm{CX}$ Amsterdam, The Netherlands; "Department of Pharmaceutics \& Center for Controlled Chemical \\ Delivery, University of Utah, 421 Wakara Way, Suite 318. Salt Lake City, UT 84108, USA
}

\begin{abstract}
The in vitro degradation properties of glutaraldehyde cross-linked albumin and albumin-heparin conjugate microspheres (AMS and AHCMS respectively) were evaluated using light microscopy, turbidity measurements and heparin release determinations, showing that the microspheres are degraded by proteolytic enzymes such as trypsin, proteinase $\mathrm{K}$ and lysosomal enzymes. The degradation rate was inversely related to the cross-link density of the microspheres. After intrahepatic administration of AHCMS, cross-linked with $0.5 \%$ glutaraldehyde, to male Wag/Rij rats by injection into a mesenteric vein (intraveno-portal: i.v.p.), the microspheres were entrapped in the hepatic vascular system. The AHCMS were entrapped within terminal portal veins predominantly at the periphery of the liver. The AHCMS were degraded by cellular enzymatic processes within 2 wk after injection, with a half life of approximately $1 \mathrm{~d}$. Biocompatibility of AHCMS and adriamycin-loaded AHCMS was evaluated by histological assessment of the mitotic activity of liver parenchym and inflammatory response, and by determination of liver damage marker enzymes during $4 \mathrm{wk}$ after administration. Liver damage marker enzymes were not increased as compared with controls, nor were adverse effects observed upon histological examination. There was no difference in response between empty and adriamycin-loaded AHCMS.
\end{abstract}

Keywords: Microspheres, chemoembolization, adriamycin, liver

Received 1 September 1993; accepted 25 October 1993

\begin{abstract}
Albumin-heparin conjugate microspheres (AHCMS) have been developed as potential adriamycin (ADR) targeting devices for the treatment of, for instance, hepatic metastases of colon carcinoma ${ }^{1,2}$. Treating liver metastases using chemoembolization therapy, the drugloaded microspheres are injected into a mesenteric vein or into the hepatic artery. It has been shown that microspheres of the appropriate size $(10-50 \mu \mathrm{m})$ are predominantly trapped in the vascular system of lumours $^{3,4}$. To achieve adequate therapeutic efficacy, it may be necessary to repeat the chemoembolization treatment several times. When non-degradable spheres are used, accumulation of foreign material in the liver occurs. This may cause unnecessary damage to the liver. Hence, the AHCMS have to be biodegradable.

Another important issue in the use of AHCMS in chemoembolization therapy is the biocompatibility of
\end{abstract}

Correspondence to Dr J. Feijen. the microspheres. Upon implantation of a foreign body, a wound healing process due to the trauma induced by the implantation procedure is provoked. Wound healing processes include an inflammatory phase, a proliferative phase and a remodelling phase The acute inflammatory response involves local accumulation of inflammatory cells, including neutrophils and monocytes/macrophages and in some instances lymphocytes ${ }^{5,6}$. This phase usually lasts several days, but may be prolonged by the presence of a foreign body. Consequently, the inflammatory response which remains after $1 \mathrm{wk}$ can be considered to be a tissue reaction against the implanted material. Chronic inflammatory responses include persistence of inflammatory cells around and inside the implant, the presence of multinucleated giant cells and persistence of a high degree of vascularization. The inflammatory phase is generally followed by the formation of a fibrotic capsule containing collagen and connective tissue cells surrounding the implant ${ }^{6}$. In general, all 
implants cause some degree of irritation and the success of an implant depends to a large extent on minimizing the inflammatory response. Since the drug-carrier system should not cause excessive adverse tissue reactions, the extent of these tissue reactions caused by the AHCMS and ADR-AHCMS was evaluated.

In this paper, the in vitro and in vivo degradation and the biocompatibility of AHCMS and ADR-loaded AHCMS are described. After implantation of biodegradable materials, two types of degradation mechanisms play an important role: non-enzymatic hydrolysis and enzymatic hydrolysis ${ }^{7,8}$. The first mechanism involves non-enzymatic hydrolysis of a polymer backbone which contains hydrolytically unstable bonds such as polycarbonates, polyesters, polyurethanes, polyorthoesters and polyamides. If a polymer contains bonds susceptible to enzymatically catalysed hydrolysis, the second mechanism generally controls the degradation. Since AHCMS are mainly prepared from the endogenous materials albumin and heparin, it is expected that the microspheres can in principle be degraded by enzymatic mechanisms.

In vitro degradation was investigated using different enzymes (trypsin, proteinase $K$, heparinase) and enzyme systems (a cocktail of lysosomal enzymes extracted from rat livers, referred to as tritosomes). In vivo degradation was investigated after intrahepatic administration of AHCMS and ADR-AHCMS in male Wag/Rij rats using light and transmission electron microscopy. Biocompatibility of the microspheres was determined by measuring the systemic blood levels of liver-specific enzymes as a marker for parenchymal damage. In addition, the histology of the 'implantation' site, with regard to acute and chronic inflammatory responses and increased mitotic activity, the latter being a measure for regeneration of damaged tissue, was evaluated using light and transmission electron microscopy.

\section{MATERIALS AND METHODS}

\section{Materials}

Albumin microspheres (AMS) and AHCMS of varying cross-linking density were prepared as described previously ${ }^{1}$. AHCMS, cross-linked with $0.5 \%$ glutaraldehyde (AHCMSO5) used in the in vivo experiments, were sieved using 10 and $25 \mu \mathrm{m}$ sieves. Sieved AHCMS05 were loaded with ADR (which was a kind gift from Farmitalia Carlo Erba, Milan, Italy) up to a drug content of $25.4 \%$, as described by Cremers et al. ${ }^{2}$. Trypsin, proteinase $\mathrm{K}$ and heparinase with specific activities of $10100,11.5$ and $2300 \mathrm{U} / \mathrm{mg}$, respectively, as indicated by the manufacturer, were obtained from Sigma Chemical Company (St. Louis, USA), Tritosomes were prepared by Dr J.M.W. Bouma, at the University of Groningen, The Netherlands, by a modification of the method of Trouet ${ }^{9}$ as described by Kussendrager et al. ${ }^{10}$. The tritosomes $(0.52 \mathrm{mg} / \mathrm{ml}$ of protein) were about 70 -fold purified with respect to the liver homogenate as determined by measuring the specific activity of acid phosphatase. All other materials were obtained in the highest possible grade from Merck (Darmstadt, Germany).

\section{Animals}

Male Wag/Rij rats, 8-12 wk old and weighing $260 \pm$ $40 \mathrm{~g}$ at the time of the experiments, were bred at the animal department of The Netherlands Cancer Institute (Amsterdam, the Netherlands) under specific pathogen-free (SPF) conditions. The animals were kept on a $12 \mathrm{~h}$ light $-12 \mathrm{~h}$ dark cycle and fed standard rat chow and plain tap water ad libitum.

\section{In vitro degradation of AMS and AHCMS}

To determine the influence of the microsphere stabilization procedure on the degradation rate, preliminary experiments with AMS, cross-linked under various conditions (listed in Table-1), were carried out. AMS (5.0 mg) were resuspended in $10 \mathrm{ml}$ of phosphatebuffered saline (PBS, $\mathrm{pH} 7.4$ ), containing $0.1 \% \mathrm{v} / \mathrm{v}$ Tween 80 . In wells of a 96-well microtitre plate, $0.05 \mathrm{ml}$ of an enzyme solution of trypsin or proteinase $\mathrm{K}(5 \mathrm{mg} / \mathrm{ml} \mathrm{PBS} / \mathrm{Tw})$ was added to $0.05 \mathrm{ml}$ of a microsphere suspension. The mixture was incubated at $37^{\circ} \mathrm{C}$. At several time points $(5,15,30,60,90,120$, $150,300,600,1440$ and $2880 \mathrm{~min}$ ), the wells were examined using a light microscope and the degradation time was taken as the time at which no single microspheres could be further detected.

In the second set of in vitro degradation experiments, $3 \mathrm{mg}$ of AHCMS or AMS were resuspended in $3 \mathrm{ml}$ of enzyme solution and kept at $37^{\circ} \mathrm{C}$ in a shaking bath. Enzyme solutions of proteinase $\mathrm{K}(0.5-5 \mu \mathrm{g} / \mathrm{ml} \mathrm{PBS})$ or trypsin (0.01-0.1 mg/ml PBS) were used; the activity of the latter solutions was also tested using an $\mathrm{N}$-benzoylL-arginine-ethyl ester (BAEE) assay as described by Bergmeyer ${ }^{11}$. At set time points, ranging from $5 \mathrm{~min}$ to $24 \mathrm{~h}$, the turbidity of the suspension was measured at a wavelength of $580 \mathrm{~nm}$ using a Uvikon 930 spectrophotometer (Kontron Instruments, Rotkreuz, Switzerland). At each time point, $150 \mu$ of the microsphere suspension were transforred to a $1.5 \mathrm{ml}$ Eppendorf ${ }^{(\ll)}$ cup and centrifuged at 12000 r.p.m. for $10 \mathrm{~s}$. Then $100 \mu \mathrm{l}$ of the supernatant were taken and used for heparin determination using the metachromic azure $A$ assay, described

Table 1 Degradation time* of albumin microspheres in enzyme systems

\begin{tabular}{lllrr}
\hline Type & $\begin{array}{l}\text { Cross- } \\
\text { linker } \\
\text { conc. }(\%)\end{array}$ & $\begin{array}{l}\text { Cross- } \\
\text { link } \\
\text { time (h) }\end{array}$ & $\begin{array}{l}\text { Trypsin } \\
\text { (min) }\end{array}$ & $\begin{array}{l}\text { Proteinase K } \\
\text { (min) }\end{array}$ \\
\hline AMS02 & 0.2 & 1 & 30 & 5 \\
AMS05 & 0.5 & 1 & 90 & 30 \\
AMS10 & 1.0 & 1 & 1440 & 120 \\
AMS15 & 1.5 & 1 & 2880 & 1440 \\
AMS30 & 3.0 & 1 & $>2880$ & 1440 \\
AMS05-05 $5^{\ddagger}$ & 0.5 & 0.5 & 30 & 30 \\
AMS05-15 & 0.5 & 1.5 & 150 & 120 \\
AMS05-30 & 0.5 & 3 & 150 & 120 \\
\hline
\end{tabular}

"Time at which single microspheres could no longer be detected using a light microscope.

Number in codes refers to glutaraldehyde concentration.

"Numbers in codes refer to glutaraldehyde concentration and cross-link time. respectively. 
by Jacques and Wollin ${ }^{12}$, as medified by Hennink $e t$ al. ${ }^{13}$. The heparin release is expressed as $A_{503}$. The enzyme in the microsphere-containing residue remaining after centrifugation was inactivated by the addition of $1 \mathrm{ml}$ acetic acid buffer $(\mathrm{pH} 4)$. These samples were stored at $-20^{\circ} \mathrm{C}$ until light microscopic analysis.

Degradation of AMS and AHCMS was also followed using a flow cytometer (FACStar ${ }^{+}$, Beckton \& Dickinson, Mountain View, CA, USA). The enzyme solution $(0.05 \mathrm{ml})$ containing proteinase $\mathrm{K}(5 \mathrm{mg} / \mathrm{ml})$, heparinase $(0.025 \mathrm{mg} / \mathrm{ml})$ or tritosomal enzymes was added to $0.5 \mathrm{ml}$ of a microsphere suspension containing $1.0 \mathrm{mg}$ of microspheres/ml of PBS. At set time points varying between $4 \mathrm{~h}$ and $11 \mathrm{~d}$, depending on the enzyme, the size distributions of the microspheres were determined. In this experiment the time point at which $75 \%$ of the particles was smaller than $10 \mu \mathrm{m}$ was taken as a measure of the degradation time.

\section{Intrahepatic degradation and biocompatibility of AHCMS}

Approximately $5 \mathrm{mg}$ of empty or ADR-loaded AHCMS, which were cross-linked with $0.5 \%$ glutaraldehyde (AHCMS05) were resuspended (using a minimal amount of ethanol for wetting of the microspheres) in $5 \% \mathrm{w} / \mathrm{v}$ glucose solution. After $2 \mathrm{~h}$ of rotation at $4 \mathrm{C}$ in the dark, the microspheres were centrifuged and the supernatant, which contained frec ADR in the case of ADR-AHCMS, was decanted. Fresh glucose solution $(0.5 \mathrm{ml})$ was added and the suspensions were administered to male Wag/Rij rats using the following surgical procedure. Under ether anaesthesia, a midline laparotomy was performed and the mesentery of the small intestine was exposed. The suspensions were then slowly injected into a mesenteric vein (intravenoportal: i.v.p.) under microscopic vision with a 30gauge needle. Afterwards, the vein was ligated. Then the syringe was refilled with $0.5 \mathrm{ml}$ of $5 \% \mathrm{w} / \mathrm{v}$ glucose solution and the microspheres that remained in the syringe after the first injection were injected into another mesenteric vein.

At $3,7,14$ and $28 \mathrm{~d}$ after i.v.p. administration of microspheres, rats $(n=2$ per time point) were anaesthetized by i.p. injection of $2 \mathrm{ml}$ of pentobarbital solution $\left(60 \mathrm{mg} / \mathrm{ml}\right.$; Nembutal ${ }^{\mathrm{K} i}$, Sanofi, France) and a laparolomy was performed. The livers were perfused via the portal vein with phosphate buffer $(0.1 \mathrm{M}, \mathrm{pH}$ 7.4) to rinse the vascular system followed by perfusion-fixation buffer $(2 \%$ glutaraldehyde in phosphate buffer, $0.1 \mathrm{M}, \mathrm{pH}$ 7.4). which allowed fixation of the tissues in situ. Subsequently, the rats were killed and the liver tissue was prepared for light microscopy by embedding in Technovit $7100^{\mathrm{k}}$ (Kulzer, Wehrheim, Germany) ${ }^{14}$. After embedding, $2 \mu \mathrm{m}$ microtome sections were cut perpendicular to the surface of the liver lobe and stained with toluidine blue and alkaline fuchsin ${ }^{15}$.

To determine the in vivo degradation rate of the microspheres, the number of microspheres in $100 \mu \mathrm{m} \times 100 \mu \mathrm{m}$ areas of the light microscope liver sections were counted. Per section, microspheres were counted in two times ten $100 \mu \mathrm{m} \times 100 \mu \mathrm{m}$ areas in two rows, as shown in Figure 1 . These numbers were

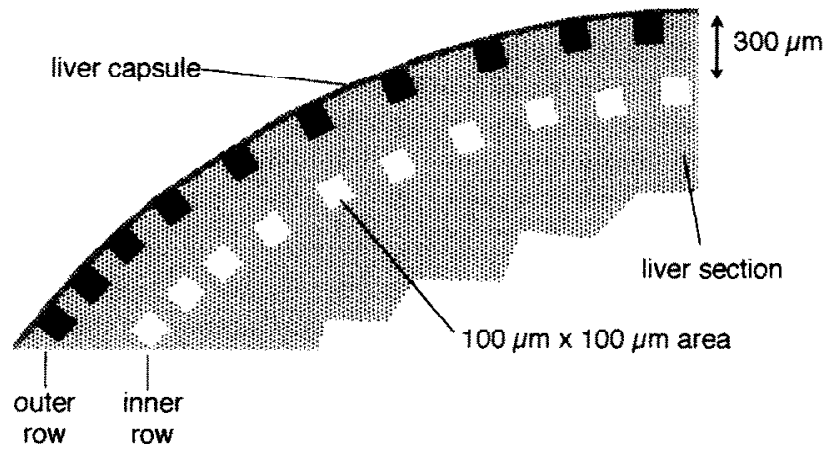

Figure 1 Schematic representation of a liver section with two rows of $100 \mu \mathrm{m} \times 100 \mu \mathrm{m}$ counting areas for determination of the average numbers of microspheres and mitotic figures per $100 \mu \mathrm{m} \times 100 \mu \mathrm{m}$ area. The first row (black squares, outer row) is at the outermost region of the liver, the second row (white squares, inner row) $300 \mu \mathrm{m}$ below the liver surface.

averaged per row. For each liver, six sections were evaluated, two in each of the large liver lobes and one in each small lobe. Next to the number of microspheres, the mitotic activity was determined as a measure for the regeneration of damaged tissue by counting the number of mitotic figures in the $100 \mu \mathrm{m} \times 100 \mu \mathrm{m}$ areas.

For transmission electron microscopy, selected parts of the liver lobes were washed with PBS and postfixed with $1 \% \mathrm{OsO}_{4}$ in PBS. After dehydration in a graded ethanol series, samples were embedded in Epon 812 . Ultrathin sections were cut and examined for cellular interactions with microspheres in a Philips 201 Transmission Electron Microscope, operated at $40 \mathrm{kV}$.

Liver damage due to the administration of microspheres was also monitored by measuring the levels of liver damage marker enzymes at $0,1,3,7,14$ and $28 \mathrm{~d}$ after administration of AHCMS $(n=2)$ or ADR-AHCMS $(n=2)$ to male Wag/Rij rats. Controls $(n=2)$ received a sham operation and were administered $1 \mathrm{ml}$ of $5 \% \mathrm{w} / \mathrm{v}$ glucose solution. Plasma levels of alkaline phosphatase, serum glutamate oxaloacetate transaminase (SGOT), serum glutamate pyruvate transaminase (SGPT), $\gamma$-glutamyl transferase $(\gamma$-GT) and lactate dehydrogenase $(\mathrm{LDH})$ were determined at the Clinical Chemical Laboratory of the Antoni van Leeuwenhoek Huis (Amsterdam, The Netherlands).

\section{RESULTS AND DISCUSSION}

The matrices of AMS and AHCMS consist predominantly of albumin. Since this is an endogenous material which is readily metabolized in the body, it may be expected that the microspheres are degraded by proteolytic enzymes. A preliminary study of the in vitro enzymatic degradation of AMS, in which the degradation time was taken as the time at which single microspheres could no longer be detected using a light microscope, was not suitable to obtain quantitative results and only some general trends could be observed. Table 1 shows that the degradation was strongly influenced by the cross-linking of the microspheres. 
The degradation time increased with higher glutaraldehyde concentrations and longer cross-link times. Trypsin is known to act specifically on the carboxylic acid side of basic amino acids such as lysine and arginine ${ }^{16}$. Since lysine residues were modified during microsphere preparation ${ }^{1}$, the efficacy of this enzyme was reduced with increasing cross-linking density. At $3 \%$ glutaraldehyde, no degradation of AMS was observed within $48 \mathrm{~h}$. Even though proteinase $K$ is not amino acid-specific (although the carboxylic acid side of aromatic or hydrophobic amino acids is preferred), the degradation rate was also decreased with increasing glutaraldehyde content. At any applied cross-linked concentration, however, microspheres could be degraded.

In the second set of experiments, the degradation of AHCMS and AMS was followed using turbidity and heparin release measurements. Figure 2 shows that AHCMS05 could also be degraded by trypsin. Enzymatic activity was evident since with increasing
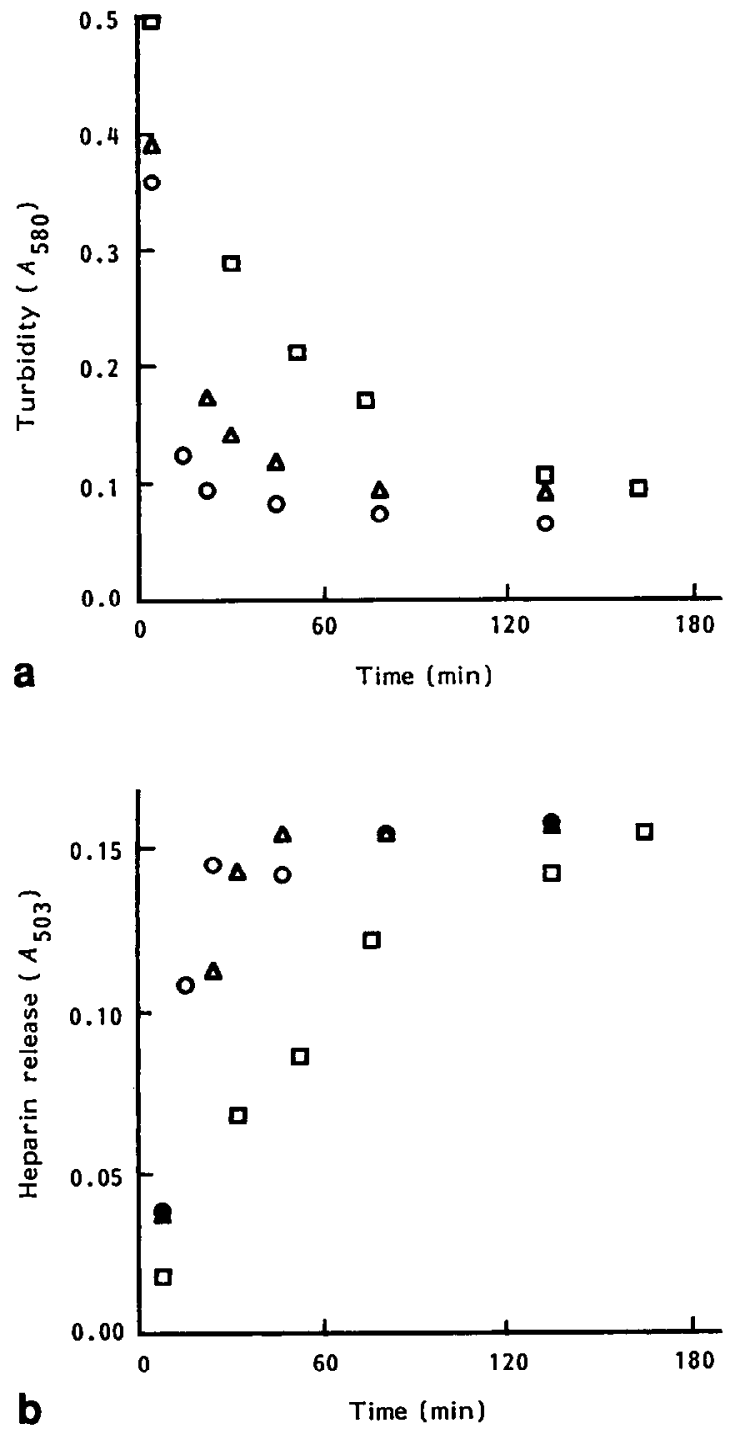

Figure 2 Degradation of AHCMSO5 in trypsin solutions of varying activity as determined by $B A E E$ assay, at $37^{\circ} \mathrm{C}$. $a$, Turbidity of microsphere suspension and $b$, heparin release as measured by Azure $A$ method. $O, 931 \mathrm{U} / \mathrm{ml}$ $\triangle, 433 \mathrm{U} / \mathrm{ml} ; \square, 149 \mathrm{U} / \mathrm{ml}$. enzyme concentrations, i.e. with increasing enzyme activity as determined by a BAEE assay, the degradation rate increased. Furthermore, in PBS no degradation of AMS and AHCMS was observed. Figure 2 also shows that turbidity and heparin release changed accordingly. With longer degradation times, the number of particles decreased and the turbidity of the suspension also decreased (Figure 2a). Heparin is not degraded by trypsin or proteinase $K$, and therefore heparin which may be linked to protein degradation products of low molecular weight will be released during degradation (Figure 2b). Both parameters, decrease of turbidity of the suspension as well as heparin release, indicated microsphere degradation. From Figures 2 and 3 it can be seen that these parameters reached plateau values at approximately the same time. The effect of the cross-link density of $\Lambda \mathrm{MS}$ on the degradation rate of these microspheres, shown in Table 1, was also observed with AHCMS.

Figure $3 a$ and $b$ shows the degradation of AHCMSO2,
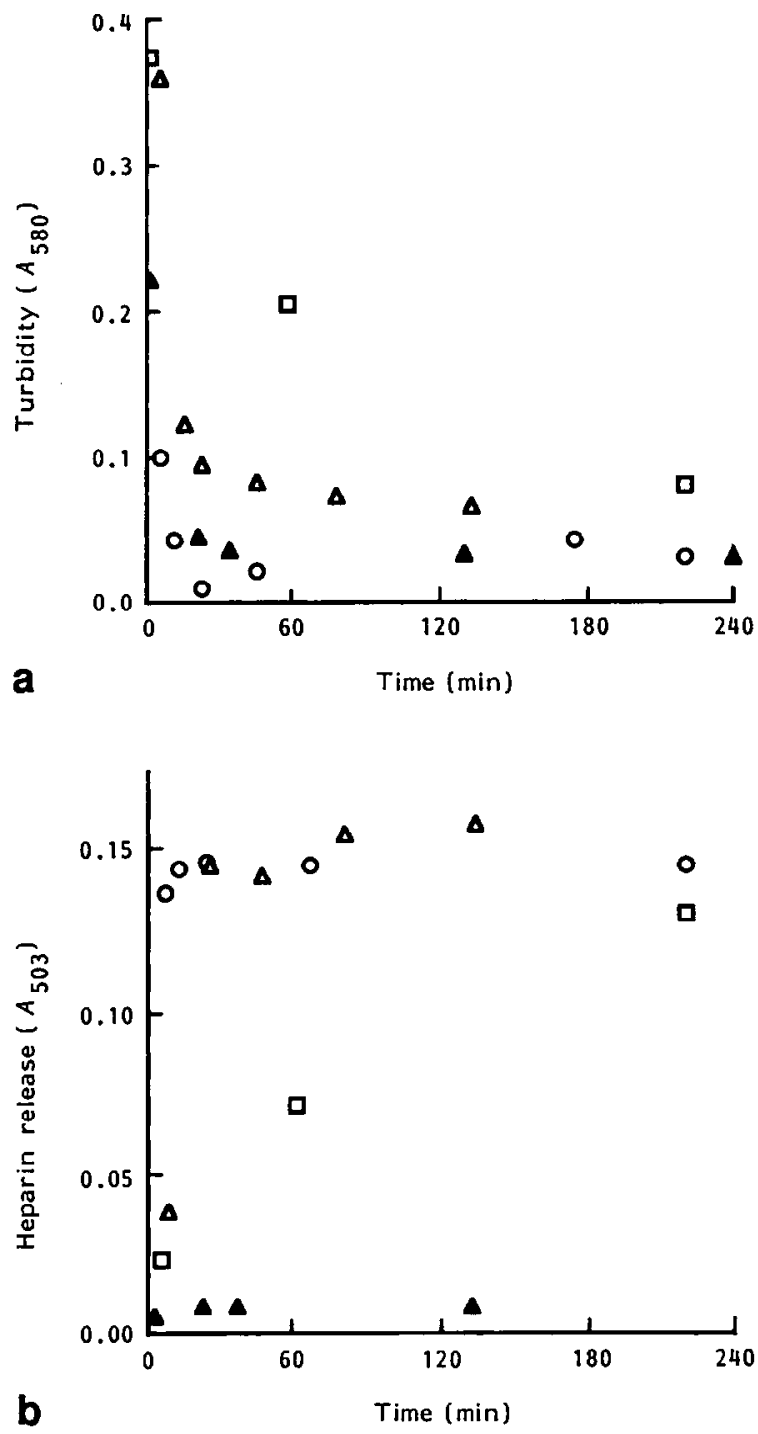

Figure 3 Degradation of AHCMS or AMS in trypsin solution of $931 \mathrm{U} / \mathrm{ml}$ at $37^{\circ} \mathrm{C}$, as determined by: a, turbidity of microsphere suspension; $b$, heparin release as measured by Azure A method. $O$, AHCMS02; $\triangle$, AHCMSO5; $\square$, AHCMS10; $\triangle$, AMS05 
AHCMS05, AHCMS10 and AMS05 in a trypsin solution of $931 \mathrm{U} / \mathrm{ml}$, as determined by the turbidity and the heparin release, respectively. With increasing glutaraldehyde content, the plateau values of both the turbidity and the heparin release were reached at longer time intervals. In the case of AMS, no heparin release was detected, as expected.

AHCMS degradation in proteinase $\mathrm{K}$ solutions showed the same trends. Figure 4 shows the turbidity and the heparin release of an AHCMS05 suspension during the degradation in a proteinase $\mathrm{K}$ solution of $0.005 \mathrm{mg} / \mathrm{ml}$ at $37^{\circ} \mathrm{C}$.

Light microscopic analysis (Figure 5) of the microspheres during this degradation process showed several stages. Initially, the spherical geometry of the microspheres was evident (Figure 5a). At this stage the azure A assay already indicated some heparin release. During the degradation process, the microspheres became disrupted (Figure $5 b$ ), while the turbidity decreased and the heparin release increased. Although disruption was already manifest, the microspheres retained their size. At the third stage (Figure $5 c$ ) the microspheres had become totally disrupted, losing their spherical geometry. Finally, almost all particulate material had disappeared (Figure 5d). During the last two stages, heparin release and turbidity barely changed.

The existence of several phases in the degradation behaviour of AMS has been described previously. Willmott et al. ${ }^{17}$ assessed the in vitro degradation of AMS in trypsin solution by laser diffraction using changes in volume concentration, which is computed from both amount of light transmitted and particle size distribution. They found a latent period before the particles appeared to 'swell' and degrade. In laser diffraction measurements, however, the size or size distribution is calculated by deconvolution of the scatter pattern. The scatter pattern is influenced by the size of the particles, the shape of the particles, the homogeneity of the particles and the relative refractive index: $n_{\text {particles }} / n_{\text {medium }}$. Changes in the volume concentrations can be caused by changes in either one of these parameters. Bearing this in mind, the latent phase would correlate with the phase depicted in Figure $5 a$ and to a lesser extent with the phase shown in Figure

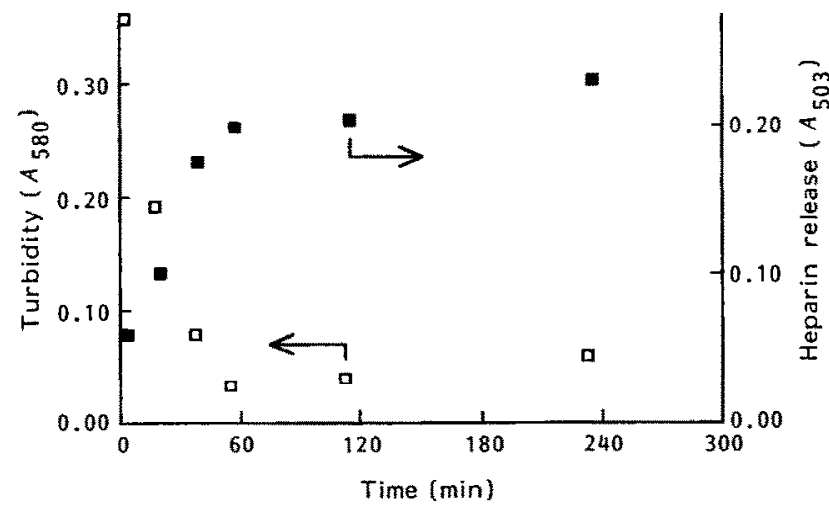

Figure 4 Degradation of AHCMSO5 in a proteinase $\mathrm{K}$ solution of $0.005 \mathrm{mg} / \mathrm{ml}$ at $37^{\circ} \mathrm{C}$ as determined by: $\square$, turbidity and $\square$, heparin release.

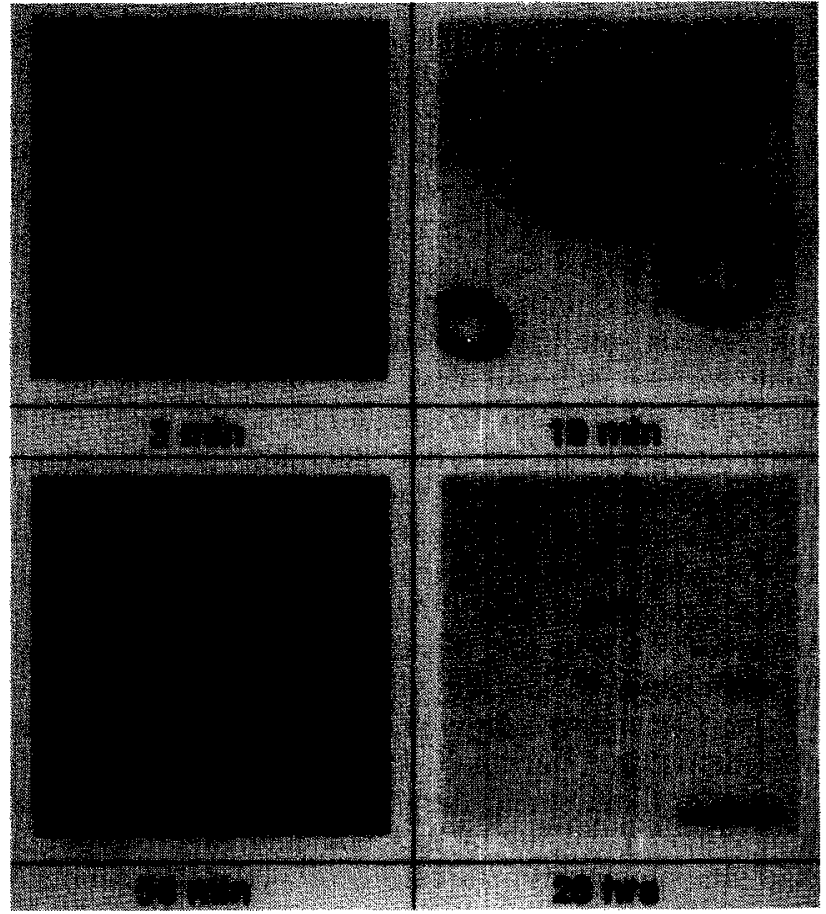

Figure 5 Light micrographs of AHCMSO5 during in vitro degradation in proteinase $\mathrm{K}$ solution $(0.005 \mathrm{mg} / \mathrm{ml})$ at $37^{\circ} \mathrm{C}$ Bar indicates $28.3 \mu \mathrm{m}$

$5 b$. The second phase, the apparent swelling phase, could also be induced by the disruption of the particles without any change in size, correlating with the degradation phases shown in Figure $5 b$ and $c$

Table 2 shows the results of the third set of in vitro degradation experiments. In these experiments, the time at which $75 \%$ of the particles were smaller than $10 \mu \mathrm{m}$ as determined using a flow cytometer was taken as a measure of the degradation time. Table 2 shows that the microspheres were easily degraded by proteinase $\mathrm{K}$, which is in agreement with the previous experiments. Under these experimental conditions, however, there is hardly any influence of the cross-link density on the degradation time. In the case of heparinase there was no sign of macroscopic degradation. During the experiment, however, it was observed that the microspheres became sticky, which resulted in a slight increase of the size of the measured particles. This

Table 2 Degradation time* (h) of albumin and albuminheparin conjugate microspheres by different enzyme systems determined using flow cytometry

\begin{tabular}{lllc}
\hline & Proteinase K & Heparinase & Tritosomes \\
\hline AMS02 $^{\dagger}$ & 2.5 & n.d. & 16 \\
AMS05 & 3 & n.d. & 28 \\
AMS10 & 3 & $\mathrm{x}^{3}$ & $\mathrm{x}$ \\
AHCMS02 & 2.5 & $\mathrm{x}$ & 9 \\
AHCMS05 & 3 & $\mathrm{x}$ & 20 \\
AHCMS10 & 3 & $\mathrm{x}$ & $\mathrm{x}$ \\
\hline
\end{tabular}

"The time at which $75 \%$ of the particles were smaller than $10 \mu \mathrm{m}$

Number in codes refers to glutaraldehyde concentration.

tn.d., not determined.

${ }_{x}$, no degradation within time of experiment. 
indicates that degradation of the heparin will not result in destruction of the microspheres, implying that the microspheres are stabilized by cross-linking of the protein chains. In the case of degradation by tritosomal enzymes, the microspheres cross-linked with 0.2 and $0.5 \%$ glutaraldehyde were degraded, whereas microspheres cross-linked with $1.0 \%$ glutaraldehyde did not show any signs of degradation in this experimental set up. This, once more, illustrates the effect of the crosslink density on the degradation behaviour. Overall, these results indicate that the microspheres are in principle susceptible to degradation in vivo, either upon endocytosis or after excretion of lysosomal enzymes in the vicinity of the microspheres.

In vivo degradation was studied by determination of the amounts of microspheres in liver tissue after i.v.p. administration of empty AHCMS05 and ADR-loaded AHCMS05. Using the described injection procedure, approximately $95 \%$ of the microspheres were injected.

It has been shown previously that, after intravascular administration, particles larger than $7-12 \mu \mathrm{m}$ are trapped in the first capillary bed encountered, and that drug-loaded particles of this size can in principle be used for site-specific targeting of cytostatic agents ${ }^{18}$. AHCMS05 which were sieved using 10 and $25 \mu \mathrm{m}$ sieves swell to a size of approximately $10-50 \mu \mathrm{m}$ upon suspension in an aqueous medium ${ }^{1}$. The light micrograph in Figure 6 shows that these particles are trapped in the vascular systom of the liver after administration into a mesenteric vein.

To determine the site of entrapment of the microspheres, the histological organization of the liver has to be clarified. Figure 7 shows a schematic representation of the architecture of the liver. Two different concepts have been distinguished. In the first concept, the classical lobule is the main building block of the liver ${ }^{19}$. The classical lobule consists of a hexagonal structure with the corners of the polygon occupied by portal canals. These portal canals consist of a small branch of the portal vein and one of the hepatic artery, as well as a bile ductule, enclosed in a common investment of connective tissue. The branches of the portal vein in the portal canals may be

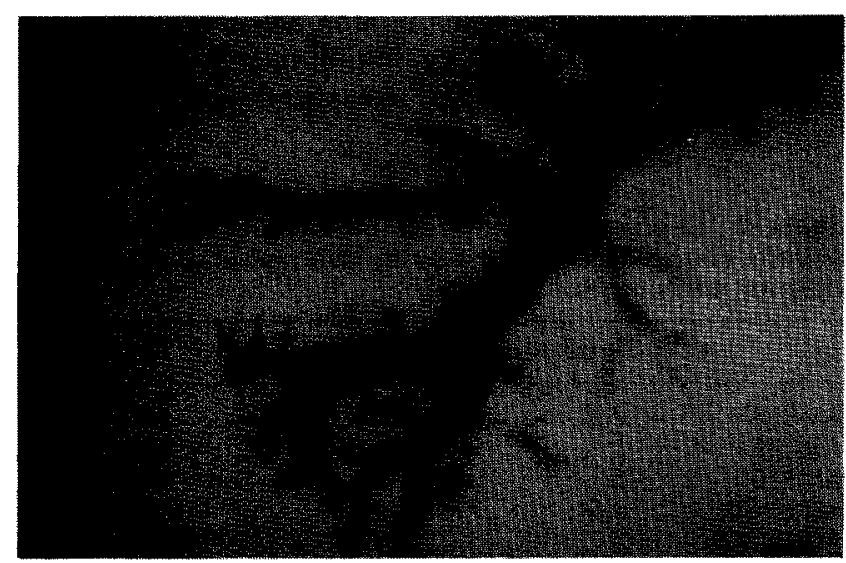

Figure 6 Light micrograph of ADR-loaded AHCMS05 (at arrows) trapped in terminal portal veins of the hepatic vascular system, $1 \mathrm{~h}$ after I.V.p. injection into a male Wag/ Rij rat. Bar indicates $37.4 \mu \mathrm{m}$.

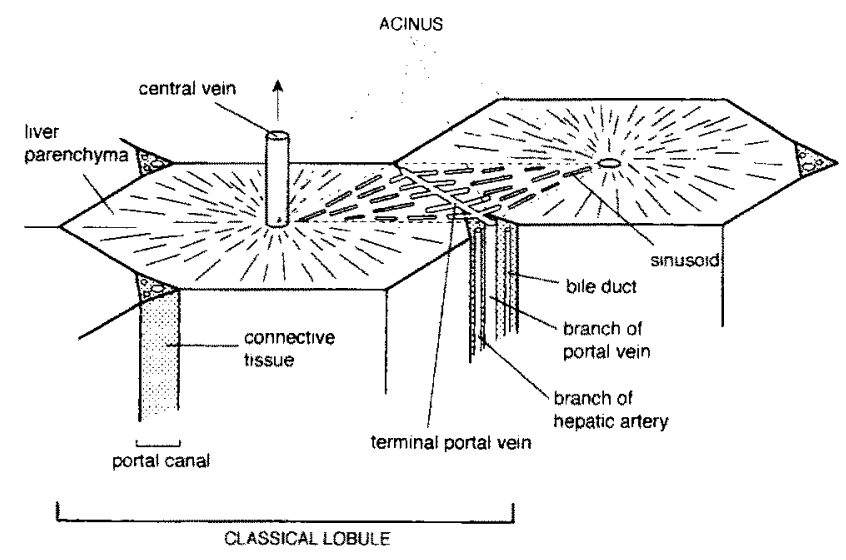

Figure 7 Schematic representation of the architecture of the liver.

up to $280 \mu \mathrm{m}$ in diameter. Blood enters the hepatic sinusoids from small branches of the hepatic artery and portal vein, flows centripetally through the liver lobules and leaves via the central vein. In the second concept, first described by Rappaport et $a .^{20}$, the building block is the acinus, which is the smallest structural and functional unit. The acinus is a mass of parenchymal tissue, associated with a fine terminal branch of the portal vein (terminal portal vein). These branches leave the portal canals at intervals and run along the side of the classical lobule. Terminal portal veins are accompanied by very sparse connective tissue, terminal branches of the hepatic artery, and the bile duct and a fine network of lymphatics ${ }^{19}$.

The micrographs depicted in Figure 8 show liver sections at 3 and $7 \mathrm{~d}$ after i.v.p. administration of empty AHCMS05. The micrographs show that the microspheres are trapped in the terminal portal veins of the liver. AHCMSO5 of $10-50 \mu \mathrm{m}$ diameter are too large to pass through the terminal branches of the portal vein and will be trapped in these branches. Almost all of the microspheres were located inside these small blood vessels. Occasionally, a small microsphere was observed within a sinusoid (see also Figure 11). Most AHCMS05 were detected in the peripheral regions of the liver lobes. Towards the periphery of the liver, blood vessels become more branched and are smaller in diameter. With decreasing size of the particles, entrapment will shift from the central parts of the liver towards the periphery. This is also depicted in Figure 9, showing the average number of AHCMS05 and ADR-AHCMS05 in $100 \mu \mathrm{m} \times 100 \mu \mathrm{m}$ areas of the liver lobes. Areas at the outmost region of the liver (outer row) as well as areas $300 \mu \mathrm{m}$ under the liver surface (inner row) were evaluated.

There was a distinct difference between the number of spheres in the outer row and in the inner row of the liver, with most microspheres being observed in the outer row. Figure 9 also shows that the number of spheres in these rows was not significantly altered if ADR-loaded AHCMS were used instead of empty AHCMS.

Figure 9 and the micrographs shown in Figure 8 show a decrease in the number of microspheres in the liver tissue in time. The highest number of spheres was observed at day 3 post-administration 

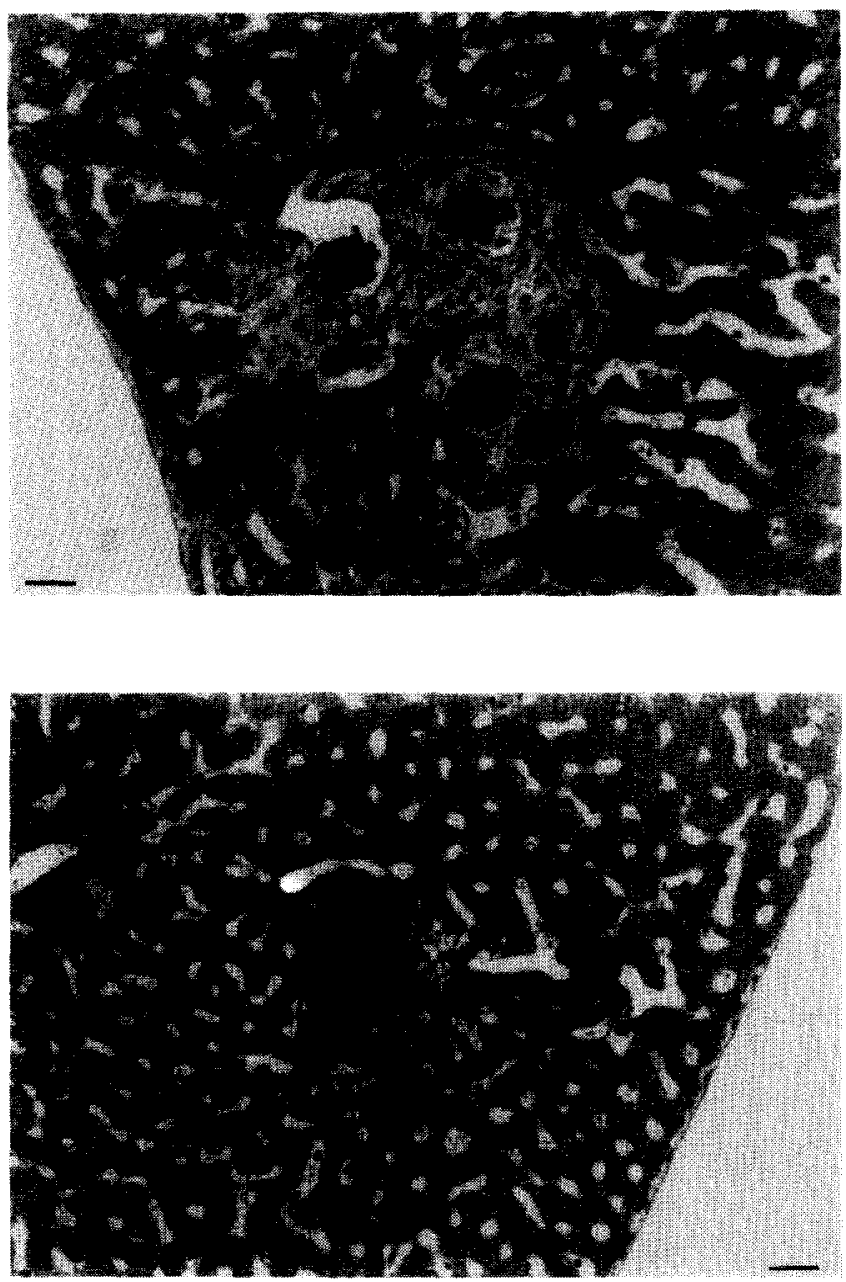

Figure 8 Histological sections of liver tissue after injection of AHCMSO5 (indicated by arrows) into a mesenteric vein of male Wag/Rij rats. a, $3 \mathrm{~d}$ after injection; b, $7 \mathrm{~d}$ after injection. Bar indicates $37.5 \mu \mathrm{m}$.

(the first day of examination), then numbers gradually decreased, and at day 14 hardly any microspheres could be found. At day 28 no microspheres could be detected.

From the decrease of the mean number of microspheres per $100 \mu \mathrm{m} \times 100 \mu \mathrm{m}$ area (per time point, per row), an intrahepatic half life of approximately $1 \mathrm{~d}$ was calculated for both empty and ADRloaded AHCMS05. Willmott et $a .^{17}$ previously determined the half life of radiolabelled AMS, crosslinked with $3.5 \%$ glutaraldehyde, to be $3.6 \mathrm{~d}$.

It was demonstrated that AHCMS could be degraded in vitro by lysosomal enzymes. The light micrographs shown in Figure 8 suggest an increased cellular activity surrounding the particles in the terminal portal veins. Terminal portal veins are sparsely surrounded by connective tissue, therefore the increased cellular activity is mainly due to the infiltration of macrophages/Kupffer colls. This was confirmed by transmission electron micrographs, as shown in Figure 10.

Engulfment of microspheres by macrophages/Kupffer cells is also demonstrated in Figure 11. This figure shows a transmission electron micrograph of a small microsphere which is engulfed by a phagocytic cell,

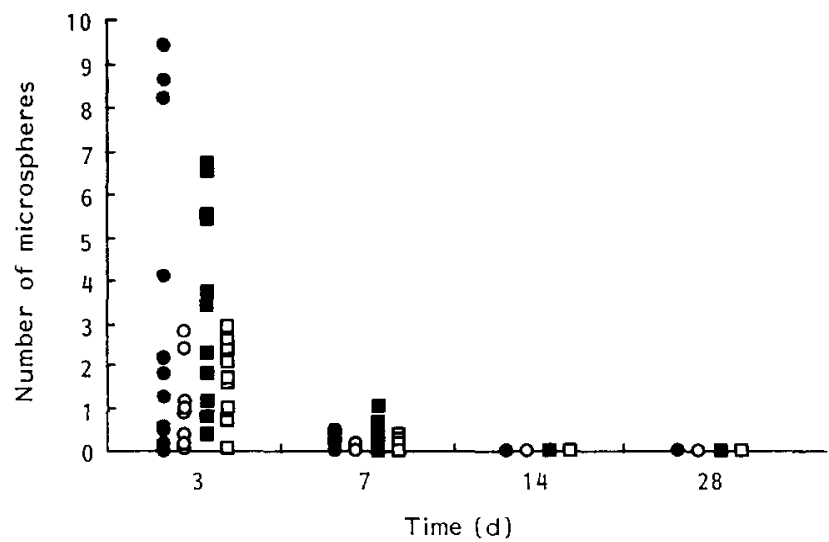

Figure 9 Number of microspheres counted in $100 \mu \mathrm{m} \times 100 \mu \mathrm{m}$ areas of the liver tissue after i.v.p. administration of AHCMS05 or ADR-AHCMS05 as a function of time. Each point represents the average number of microspheres in 10 areas in one section. AHCMSO5, outer row: O, AHCMS05, inner row; $\mathbf{n}$ ADR-AHCMS05, outer row; $\square$, ADR-AHCMSO5, inner row.

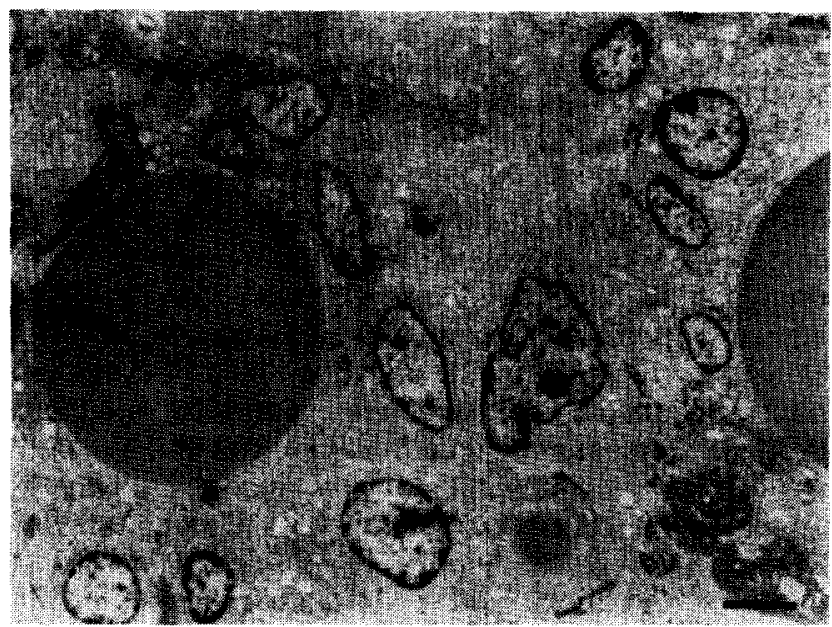

Figure 10 Transmission electron micrograph from albumin-heparin conjugate microspheres, cross-linked with $0.5 \%$ glutaraldehyde, lodged in the liver, $3 \mathrm{~d}$ postadministration. The microspheres present in terminal portal veins are surrounded by macrophages/Kupffer cells. Bar indicates $2.9 \mu \mathrm{m}$

ludged in a sinusoid. The lysosomal compartments are all situated near the microsphere surface. These findings suggest that the microsphercs are exposed to enzymatic degradation upon engulfment by macrophages/Kupffer cells.

The in vitro degradation experiments showed that the microspheres were disrupted during enzymatic degradation. Figure $8 b$ shows AHCMS which were partly degraded. It may be conceived that smaller parts of destructed microspheres which are not engulfed by phagocytic cells flow through the small branches of the portal veins during the in vivo degradation process. If these parts are large enough, they will be trapped in the sinusoids or the lungs. However, no microsphere fragments were found in the sinusoids, nor were traces of microspheres found on examination of the lungs at days 14 and 28 . In conclusion, these observations suggest that the microspheres were probably degraded 


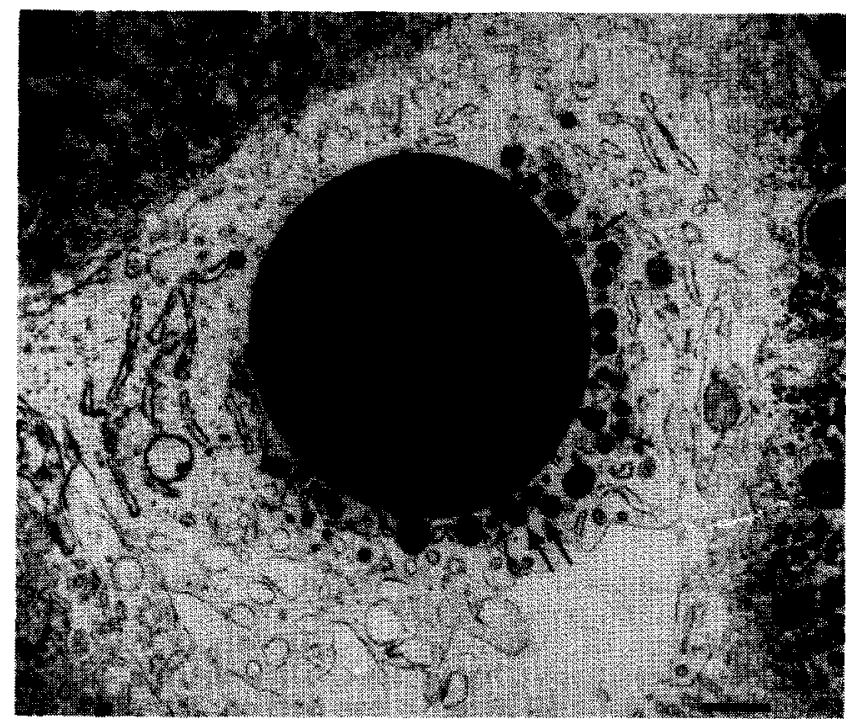

Figure 11 Transmission electron micrograph from an albumin-heparin conjugate microsphere, cross-linked with $0.5 \%$ glutaraldehyde, lodged in the liver, $3 \mathrm{~d}$ post-administration. The microsphere, present in a sinusoid, surrounded by hepatocytes, is engulfed by a Kupffer cell. Lysosomal compartments of the cell (at arrows) are fusing with the microsphere-containing vacuole. Bar indicates $0.65 \mu \mathrm{m}$.

upon phagocytosis of the entire particle, or by excretion of lysosomal enzymes, yielding soluble products and/or microsphere debris. These results are in good agreement with data previously published by Willmott et $a .^{17}$. During the degradation of ${ }^{125} \mathrm{I}$-AMS, no accumulation of radiolabel was found in the lungs. Protein microspheres, when degraded in the liver, did not appear to relocate to any marked extent to 'downstream' organs such as lungs and bone marrow. The authors concluded that the originally entrapped particles are not eroded to particles of smaller diameter and that a more likely explanation is that the particles are degraded into soluble protein/peptide fragments at the site of entrapment.

The tissue reaction caused by the microspheres may be considered to be very mild. The increased macrophage/Kupffer cell activity around the microspheres, shown in Figures 8 and 10 , suggests that the microspheres provoked a foreign body reaction, which is defined as 'a variation in normal tissue behaviour caused by the presence of a foreign body' ${ }^{21}$. The foreign body reaction was localized and ended as soon as the microspheres were degraded. No further signs of acute or chronic inflammatory responses were observed. Moreover, the mitotic activity of the livers was evaluated as a measure of the regeneration of damaged tissue. Compared with controls, which did not receive any treatment, no increase in mitotic activity was found (data not shown).

The biocompatibility of the microspheres was also evaluated by monitoring the plasma levels of liver damage marker enzymes. In Figure 12, the enzyme levels are presented relative to the enzyme levels in control animals, which were injected with $1 \mathrm{ml}$ of $5 \% \mathrm{w} / \mathrm{v}$ glucose solution. Except for SGPT levels at day 1 , the levels of the marker enzymes were barely increased as compared with the controls. This suggests
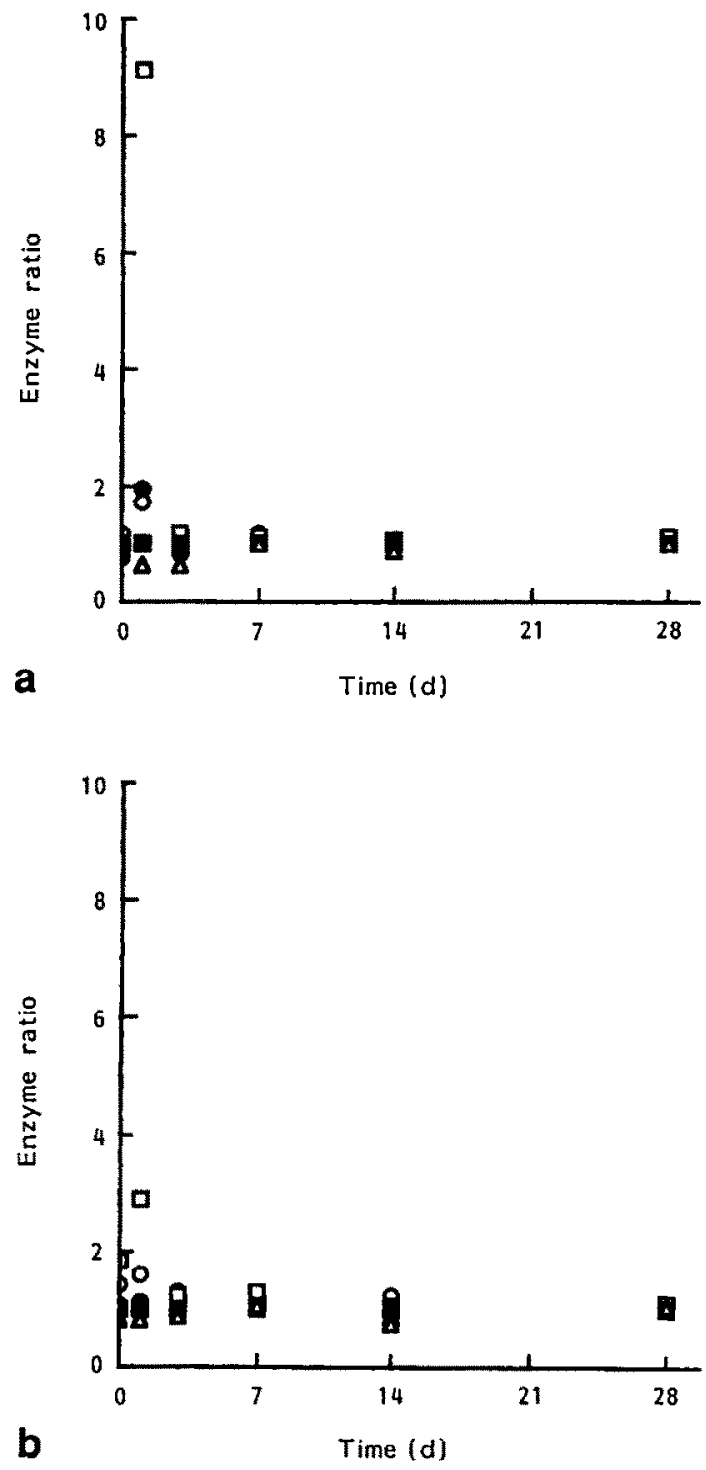

Figure 12 Levels of damage marker enzymes, relative to levels in control animals which were injected with $5 \% \mathrm{w} / \mathrm{v}$ glucose solution. a, AHCMSO5; b, ADR-AHCMS05. $O$, Alkaline phosphatase; - serum glutamate oxaloacetate transaminase (SGOT); $\square$, serum glutamate pyruvate transaminase (SGPT);,$\gamma$-glutamyl transferase $(\gamma$-GT); $\triangle$, lactate dehydrogenase $(\mathrm{LDH})$.

that the microspheres, with or without ADR, cause little damage to the liver, as far as this can be determined from these biochemical parameters.

In conclusion, these results indicate that injection of AHCMS05 into the liver has minimal effects on the liver tissue, possibly with little effect on the liver function or little clinical liver damage. Incorporation of ADR into the microspheres did not change these results. This is probably due to rapid elimination of the $A D K$ in the liver. It was demonstrated that after administration of ADR-AHCMS to male Wag/Rij rats, at a dose of $5 \mathrm{mg} \mathrm{ADR} / \mathrm{kg}$, which is comparable to the dose administered in these experiments, the ADR liver tissue levels had decreased from $37 \mu \mathrm{g} / \mathrm{g}$ at $15 \mathrm{~min}$ after administration to approximately $5 \mu \mathrm{g} / \mathrm{g}$ of tissue at $4 \mathrm{~h}$ after administration ${ }^{22}$. Rapid elimination of ADR was also observed in humans, where $50 \%$ of the drug is eliminated during the first transit through the liver ${ }^{23}$. 
Moreover, only mild liver cell changes have been demonstrated after anthracycline treatment and they could have been secondary to damage of other tissues. However, mechanisms of anthracycline toxicity are poorly understood and it has been demonstrated that rat hepatocytes are more sensitive to ADR than human hepatocytes, at $24 \mathrm{~h}$ exposure to ADR in culture ${ }^{24}$.

\section{CONCLUSIONS}

In vitro degradation experiments showed that AHCMS can be degraded by proteolytic enzymes via degradation of the protein moieties of the matrix. The in vitro degradation rate is mainly controlled by the cross-link density of the microspheres, and decreases with increasing degree of cross-linking.

I Jpon i.v.p. injection into the liver, the microspheres are trapped in the hepatic vascular system, mainly at the periphery of the liver. The microspheres are degraded at the site of entrapment by cellular enzymatic processes. No adverse effects as measured by liver damage marker enzymes and signs of prolonged chronic inflammatory responses or increased mitotic activity were observed, indicating that the carrier is well tolerated after intrahepatic administration. Incorporation of adriamycin in the carrier did not change these findings. In conclusion, these results suggest that ADR-loaded AHCMS can in principle be used in the treatment of liver metastases or in adjuvant therapy, without damaging the liver.

\section{ACKNOWLEDGEMENTS}

Thanks are due to the Netherlands Organization for Scientific Research (NWO) and Theratech Inc., SLC, Utah, for financially supporting this research and Farmitalia Carlo Erba for the kind gift of adriamycin. Dr J.M.W. Bouwma, from the University of Groningen, is acknuwledged for the preparation of the tritosomes. Jasper Donker is acknowledged for his contribution to the in vitro degradation experiments. The authors also wish to thank Drs Marja van Luyn and Pauline van Wachem from the Laboratory for Histology and Cell Biology at the University of Groningen for contributing to the evaluation of the histological sections.

\section{REFERENCES}

1 Cremers HFM, Kwon GS, Bae YH et al. Preparation and characterization of albumin-heparin microspheres Biomaterials 1993; 15: 38-48.

2 Cremers HFM, Verrijk R, Noteborn HPJM el al. Adriamycin loading and release characteristics of albumin-heparin conjugate microspheres. I Contr. Rel 1994; 29: 143-155.

3 Meade VM, Burton MA, Gray BN, Self GW. Distribution of different sized microspheres in experimental hepatic tumours. Eur J Cancer Clin Oncol 1987; 23: 37-41.

4 Anderson, JH, Angerson WJ, Willmott N, Kerr DJ, McArdle CS, Cooke TG. Regional delivery of microspheres to liver metastases: the effects of particle size and concentration on intrahepatic distribution. $\mathrm{Br}$ I Cancer 1991; 64: 1031-1034.

5 Anderson JM, Miller KM. Biomaterial biocompatibility and the macrophage. Biomaterials 1984; 5: 5-10.

6 Silver F, Doillon C. Biocompatibility-Interactions of Biological and Implantable Materials. Vol 1. Polymers. New York: VCH, 1989.

7 Kopecek J, Rejmanova P. Enzymatically degradable bonds in synthetic polymers. In: Bruck $\mathrm{SN}$, ed. Controlled Drug Delivery, Vol II, Basic Concepts. Boca Raton, FL: CRC Press, 1983: 81-124.

8 Zaikov GE. Quantitative aspects of polymer degradation in the living body. JMS-Rev Macromol Chem Phys 1985; 25: 551-597.

9 Trouet A. Isolation of modified liver lysosomes. Meth Enzymol 1974; 31: 323-329.

10 Kussendrager KD, de Jong Y, Bnuma JMW, Gruber M The digestion of the B-chain of oxidized insulin by extracts of rat liver lysosomes. Biochim Biophys Acta 1972; 279: 75-86.

11 Bergmeyer HU. Methoden der Enzymatischen Analyse, 3. Neuarbeitete und erweiterte Auflage, Band 1 Weinheim: Verlag Chemie GmbH, 1973: 551.

12 Jacques LB, Wollin A. A modified method for the colorimetric determination of heparin. Can J Phys Pharm 1967; 45: 787-794.

13 Hennink WE, Feijen J, Ebert CD, Kim SW. Covalently bound conjugates of albumin and heparin: synthesis, fractionation and characterization. Thromb Res 1983; 29: 1-13.

14 Gerrits PO, Smid L. A new, less toxic polymerization system for the embedding of soft tissues in glycol methacrylate and subsequent preparing of serial sections. J Microsc 1983: 132: 81-85.

15 Blaauw EH, Jonkman MF, Gerrits PO. Rapid connective tissue stain for glycol methacrylate embedded tissue Acta Morph Neerl-Scand 1988; 25: 167-172.

16 Bond JS. Commercially available proteases. In: Beynon RJ, Bond JS, eds. Proteolytir Enzymes, A Practical Approach. Oxford: IRL Press, 1989: 232-240.

17 Willmott N, Chen Y, Goldberg J, McArdle CS, Florence AT. Biodegradation rate of embolized protein microspheres in lung, liver and kidney of rats. J Pharm Pharmac 1989; 41: 433-438.

18 Tomlinson E. Passive and active vectoring with microparticles: localization and drug release. I Contr ReI 1985; 2: 385-391.

19 Bloom W, Fawcett DW. A Textbook of Histology, 11th edn. Philadelphia: WB Saunders, 1986: 679-715.

20 Rappaport AM, Borowy ZJ, Lougheed WM, Lotto WN. Subdivision of hexagonal liver lobules into a structural and functional unit; role in hepatic physiology and pathology. Anat Rec 1954; 119: 111.

21 Williams DF. Definitions in biomaterials. Proc Consensus Conference of the Eur Soc Biomat, Cluster England, 1986. Amsterdam: Elsevier, 1987.

22 Cremers HFM, Verrijk R, Bayon LG et al. Improved distribution and reduced toxicity of adriamycin bound to albumin-heparin microspheres. Br J Cancer 1993: submitted for publication.

23 Speth PAJ, van Hoesel, QGCM, Haanen C. Clinical pharmacokinetics of doxorubicin. Clin Pharmacokin 1988; 15: 15-31.

24 Le Bot MA, Bégué, JM, Kernaleguen D et al. Different cytotoxicity and metabolism of doxorubicin, daunorubicin, epirubicin, esorubicin and idarubicin in cultured human and rat hepatocytes. Biochem Pharmac 1988 37: 3877-3887. 